Int. J. Dev. Biol. 62: 195-205 (2018)

https://doi.org/10.1387/ijdb.170298as

\title{
Specification of sensory placode progenitors: signals and transcription factor networks
}

\author{
ANDREA STREIT* \\ Centre for Craniofacial \& Regenerative Biology, Division of Craniofacial Development \& Stem Cell Biology, \\ Dental Institute, King's College London, London UK
}

\begin{abstract}
Sensory placodes contribute to much of the sensory nervous system in the vertebrate head. They give rise to parts of the eye, ear and nose, as well as to the sensory ganglia that innervate the face, tongue, oesophagus and visceral tissues. Despite their diversity, during development placodes arise from a population of common progenitor cells, which are first specified at the border of the neural plate. The chick has been particularly instrumental in dissecting the timing of these events, and recent evidence has highlighted the close relationship of placode progenitors and precursors for neural crest cells and the central nervous system. This review focuses on the induction of placode progenitors by localised signalling events, and the transcriptional networks that lead to their specification.
\end{abstract}

KEY WORDS: chick, ear, eye, induction, olfactory epithelium, sensory ganglia, transcription factor

\section{Introduction}

The sensory placodes are unique to vertebrates and give rise to much of the peripheral nervous system in the head (for review: (Baker and Bronner-Fraser, 2001, Schlosser, 2006, Streit, 2008). They generate the lens of the eye, the olfactory epithelium that lines the nasal cavity, the entire inner ear including the cochlearvestibular ganglion, the amniote paratympanic organ, the adenohypophysis and, together with neural crest cells, form the cranial sensory ganglia (Fig. 1A). Because of their vital contribution to the sense organs and their crucial role in craniofacial morphogenesis, understanding placode development has revealed much about the cellular and molecular causes of craniofacial malformations and sensory disorders. Like neural crest cells, placode precursors are induced from the neural plate border region soon after gastrulation, and occupy the cranial ectoderm surrounding the future fore-, mid- and hindbrain, but are absent from the trunk (Fig. 1C). This territory is known as the pre-placodal region (PPR) and contains sensory progenitors that are initially competent to give rise to all placodes (Saint-Jeannet and Moody, 2014, Streit, 2007). As development proceeds, placode precursors become different from each other and coalesce to form patches of thickened tissue that line the closing neural tube (Fig. 1B). While ganglia producing placodes are simple neurogenic patches from which neuroblasts delaminate, those contributing to sense organs invaginate to form cup-like structures or vesicles, which are then transformed into more complex organs. Over time, placodes give rise to many different cell types from simple lens fibre cells to sophisticated mechanosensory hair cells in the ear, paratympanic organ and the lateral line; except for the lens and anterior pituitary all placodes produce neurons.

While placodes and their contribution to the sensory nervous system was first recognised in the late $19^{\text {th }}$ century (Beard, 1886, Froriep, 1885, Knouff, 1935, van Wijhe, 1883), it is only in the last 15-20 years that the molecular mechanisms controlling their formation are beginning to be elucidated. While some of the earliest studies largely focused on amphibians, the original fate maps from the LeDouarin (Couly and Le Douarin, 1988, Couly and Le Douarin, 1985, Couly and Le Douarin, 1987) and Noden groups (d'AmicoMartel and Noden, 1980, D'Amico-Martel and Noden, 1983) set the scene for placode studies in avian embryos. Because of its amenability for experimental manipulations including temporally and spatially controlled gene knock-down or misexpression, the ease to isolate defined tissues, and its relatively slow development compared to fish and amphibians, the chick has been particularly useful to dissect placode formation over time and to unravel the molecular hierarchy involved. This review focuses on the earliest steps of placode formation, the induction of placode progenitors from the neural plate border, the transcriptional hierarchy that

Abbreviations used in this paper: NPB, neural plate border; PPR, pre-placodal region. *Address correspondence to: Andrea Streit. Centre for Craniofacial \& Regenerative Biology, Division of Craniofacial Development \& Stem Cell Biology, Dental
Institute, King's College London, London SE1 9RT, UK. E-mail address: andrea.streit@ kcl.ac.uk (iD http://orcid.org/0000-0001-7664-7917 
specifies placode progenitors and the similarities of this process with induction of the central nervous system.

\section{Sensory placode derivatives}

In avian embryos, morphological placodes are first visible around the time of neural tube closure (Fig. 1B) (for review, see Baker and Bronner-Fraser, 2001; Schlosser, 2006; Streit, 2008). Unlike all other placodes, the adenohypophysis and the lens do not generate any neurons. The adenohypophyseal placode develops in the anterior midline, next to the ventral forebrain, forms the anterior part of the pituitary and generates a variety of neuroendocrine cells. The lens placode develops next to the optic vesicle and differentiates into the fibre and epithelial cells of the crystalline lens. The purely neurogenic placodes - the ophthalmic and maxillomandibular trigeminal and the epibranchial placodes - produce delaminating neuroblasts that form the distal portions of the $\mathrm{V}^{\text {th }}, \mathrm{VII}^{\text {th }}, \mathrm{IX}^{\text {th }}$ and $X^{\text {th }}$ cranial ganglia. The epibranchial placodes are located dorsal to the branchial clefts, and their neurons (VII ${ }^{\text {th }}$, IX ${ }^{\text {th }}$ and $\mathrm{X}^{\text {th }}$ ganglia) innervate taste buds in the oral cavity to provide gustatory information, the heart and other visceral organs for viscerosensory input. Originating next to the midbrain, trigeminal placode-derived neurons ( $V^{\text {th }}$ ganglion) transmit somatosensory information like temperature, touch and pain from the face. In amniotes, a recently discovered paratympanic placode lies close to the most rostral epibranchial placode (geniculate), and forms a hair cell containing pouch in the middle ear and its afferent neurons (O'Neill et al., 2012). The paratympanic organ may respond to changes in air pressure. In aquatic vertebrates the lateral line system is responsible for the detection of water movement and electrical fields, and originates from two sets of placodes rostral and caudal to the ear. Finally, the olfactory and otic placodes develop next to the future olfactory bulb and the hindbrain, respectively, and after invagination, undergo morphogenesis to form more complex structures. The olfactory placode generates olfactory sensory neurons, stem cells that regenerate these neurons throughout life as well as diverse migratory neurons that leave the placode and enter the brain. The otic placode arguably forms the most complex sense organ: the auditory and vestibular parts of the inner ear, including sensory hair cells, the neurons that innervate them and many other cell types like supporting and endolymph secreting cells. Thus, sensory placodes generate an incredible diversity of structures and differentiated cell types, and it is therefore surprising that their progenitors in the PPR initially share a common molecular signature as well as the same developmental potential and properties.

\section{The pre-placodal region: a unique territory of sensory placode progenitors}

Many early avian fate maps explored the derivatives of sensory placodes (e.g. (Couly and Le Douarin, 1985, Couly and Le Douarin, 1987, D’Amico-Martel and Noden, 1983, Noden, 1992), focusing on stages just before or after placodes become morphologically distinct. More recent studies investigating the origin of placodes showed that a continuous and unique territory of sensory progenitors can first be identified at head process stages (Bhattacharyya et al., 2004, Sanchez-Arrones et al., 2017, Streit, 2002, Xu et al., 2008): labelling experiments reveal a continuous band of ectoderm surrounding the anterior neural plate that contains precursors for all sensory placodes and has therefore been termed the pre-placodal region (PPR). An equivalent territory has also been identified by fate mapping experiments in Xenopus and fish (Bhat and Riley, 2011, Dutta et al., 2005, Kozlowski et al., 1997, Pieper et al., 2011). Within the PPR, precursors for different placodes are initially intermingled with each other and with progenitors for the neural plate, neural crest and epidermis, although the degree of mixing may differ in different species (Bhat and Riley, 2011, Bhattacharyya et al., 2004, Pieper et al., 2011, Streit, 2002, Xu et al., 2008); for review, see: Schlosser, 2006, 2010; Streit, 2007, 2008). Recent evidence suggests that they are multipotent progenitors with the potential to produce all ectodermal derivatives even at somite stages, when the neural tube is about to close (Roellig et al., 2017). As development proceeds, placode progenitors segregate from other ectodermal derivatives, but it is only after neural tube closure that they converge to form distinct placodes (Bhattacharyya et al., 2004, Steventon et al., 2016, Streit, 2002, Xu et al., 2008). Recent experiments in Xenopus suggest that this may at least in part be driven by neural crest cells as they migrate to form the craniofacial skeleton (Steventon et al., 2016, Theveneau et al., 2013).

In addition to harbouring all placode progenitors, the PPR also has a characteristic molecular signature (see also below), although only few genes have been identified that uniquely label this territory. Among them Six and Eya family members not only serve as molecular PPR markers, but are also critically important for its specification, for placode formation and the differentiation normal sense organs and cranial ganglia (for review, see: Schlosser, 2006,
A

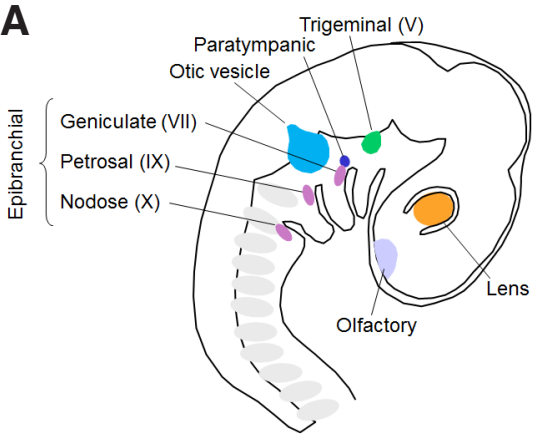

B

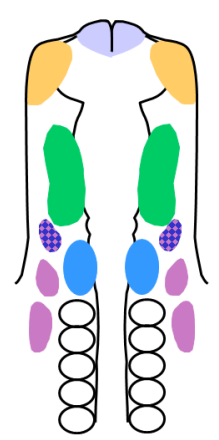

C

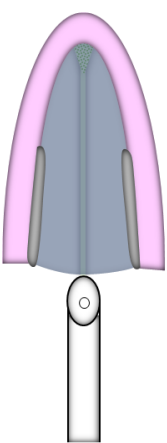

Fig. 1. Location and derivatives of placodes in the chick. (A) Diagram showing a side view of a chick embryo 3-4 days after laying and the position of different placodes. (B) Diagram of a 10-somite stage chick embryo. The olfactory placodes (light purple) are located anteriorly next to the future olfactory blub, the lens placode (orange) lies next to the optic vesicle and the trigeminal (green) next to the midbrain. The otic placode (blue) is found next to the hindbrain, and the three epibranchial placodes (pink) surround it more laterally. The paratympanic placode may occupy the same

territory as the first epibranchial placode (geniculate; blue/pink), although there are currently no fate maps for this placode at this stage. (C) The preplacodal region (pink) surrounds the anterior neural plate (blue/grey); neural crest cells (light grey) are absent from the most anterior neural plate border. 
2010; Streit, 2007, 2008). In vertebrates, six Six genes (Six1-6) and four Eya genes (Eya1-4) have been identified, of which Six1, -2, and -4 and Eya1 and -2 are expressed in placode progenitors (Ahrens and Schlosser, 2005, Bessarab et al., 2004, Esteve and Bovolenta, 1999, Ishihara etal., 2008, Kobayashi etal., 2000, Litsiou et al., 2005, McLarren et al., 2003, Mishima and Tomarev, 1998, Pandur and Moody, 2000). Six proteins are transcription factors that bind DNA through their homeodomain, while an N-terminal Six domain mediates the interaction with cofactors (for review, see: Kawakami, 2000; Donner, 2004; Hanson, 2001; Jemc, 2007). In a complex with other nuclear factors like Groucho or Dach, they are transcriptional repressors, while they act as transcriptional activators together with Eya proteins (Kenyon et al., 2005, Kobayashi et al., 2001, Li et al., 2003, Ohto et al., 1999, Patrick et al., 2013, Pignoni etal., 1997, Rayapureddi et al., 2003, Tessmar et al., 2002, Tootle et al., 2003, Zhu et al., 2002). Within the PPR, Six1 appears to play a dual role. Misexpression of Six1 alone or together with Eya2 promotes the expression of other pre-placodal genes, while simultaneously suppressing neural crest and neural plate specific factors (Brugmann et al., 2004, Christophorou et al., 2009) although it is currently unknown whether these genes are direct or indirect targets. In contrast, Six1 knock down in frog (Brugmann et al., 2004) or misexpression of a constitutive repressor form in chick (Christophorou et al., 2009) leads to loss of placode progenitors and placodal defects. In mouse, loss of Six1, Six5, Eya1 and/or Eya4 function results in defects of the olfactory epithelium, the eye and ear, as well as of the cranial ganglia. In line with these findings, mutations in the corresponding human genes are associated with various defects in sense organs including hearing loss. Thus, a large body of evidence implicates Six and Eya genes in the early specification of placode progenitors and in the maturation and differentiation of sensory placodes. Several reviews have summarised their molecular interactions and their function in development and disease in more detail (Donner and Maas, 2004, Grocott et al., 2012, Hanson, 2001, Jemc and Rebay, 2007, Kawakami et al., 2000, Saint-Jeannet and Moody, 2014, Schlosser, 2014, Xu, 2013).

Surprisingly, recent molecular screens for genes coregulated with Six1/4 and Eya2 in the chick have only identified one other transcript with PPR-specific expression, Homer2 (Hintze et al., 2017, Lleras-Forero et al., 2013). Homer2 is expressed in sensory progenitors and then becomes confined to the otic and olfactory placodes (Anwar et al., 2017, Hintze et al., 2017). However, unlike Six 1 it is already present at gastrulation stages in much of the non-neural ectoderm. These observations highlight Six/Eya factors as unique markers for sensory progenitor cells, and together with their functional importance identify them as key regulators of placodal fates.

Finally, cells in the PPR also possess unique properties that distinguish them from other ectodermal derivatives: they are uniquely competent to respond to placode inducing signals and initially share a developmental programme. Classical experiments performed in amphibian embryos suggested that at early stages all placode progenitors are competent to become any placode (Jacobson, 1963a, Jacobson, 1963b): when the placodal ectoderm is rotated along the rostro-caudal axis at neural plate stages, such that future otic cells are now in the position of the olfactory epithelium, cells adopt a new fate according to their new position. However, when the same experiment is performed later cells retain their original identity, although inter-placodal regions can still respond to new signals. Similar rotations were not performed in avian embryos, however in the beginning of the $21^{\text {st }}$ century competence and commitment was tested in many transplantation experiments using chick-quail chimera and newly available molecular markers (Baker et al., 1999, Bhattacharyya and Bronner-Fraser, 2008, Groves and Bronner-Fraser, 2000). Together these findings suggest that only the head ectoderm is competent to respond to placode inducing signals and depending on timing this property is indeed restricted to the PPR. Thus, the PPR represents a unique placode-competence field. In addition, there is strong evidence that ectodermal cells must first acquire a 'PPR state' before they can form a placode (Martin and Groves, 2006). When PPR cells from head fold stages are exposed to an otic inducer FGF2 in vitro, they rapidly turn on the ear programme (Anwar et al., 2017, Martin and Groves, 2006), while early gastrula ectoderm is not responsive. However, when the same gastrula ectoderm is first transplanted into the PPR, where it initiates expression of PPR markers like Eya2, it can now respond to FGF2 and express ear-specific genes (Martin and Groves, 2006). This finding suggests that ectodermal cells can only respond to placode inducing signals once they have acquired PPR identity and that placode induction requires at least two consecutive steps, if not more (see also: Anwar et al., 2017; Chen et al., 2017).

In chick, specification assays reveal that at head fold stages, cells in the PPR are specified as placode progenitors (Bailey et al., 2006). When cultured in isolation they continue to express the PPR markers Six 1 and Eya2. Surprisingly, all placode progenitors, even those fated to become ear and cranial ganglia, also initiate Pax6 expression, which is normally confined to the lens, olfactory and adenohypophyseal territories, and after 3-days' culture transform into lens-like vesicles expressing L-maf, FoxC1, $\alpha$ - and $\delta$-crystalline (Bailey et al., 2006). Thus, all placode progenitors are initially specified as lens irrespective of their later fate. In addition, these findings suggest that placode inducing signals not only actively promote placode identity, but simultaneously must repress lens. FGFs may be key to initiate lens repression and have been implicated in the induction of most placodes. Activation of FGF signalling suppresses lens specification in vitro and lens formation in vivo, and is required for the formation of the olfactory, trigeminal, otic and epibranchial placodes in chick and other vertebrates (Bailey et al., 2006, Canning et al., 2008, Freter et al., 2008, Ladher et al., 2000, Maroon et al., 2002, Martin and Groves, 2006, Nechiporuk et al., 2007, Nechiporuk et al., 2005, Nikaido et al., 2007, Phillips et al., 2001, Sun et al., 2007, Wright and Mansour, 2003).

In summary, at head fold stages the PPR represents a contiguous band of ectoderm surrounding the future fore-, mid- and hindbrain that is characterised by unique features: it contains precursors for all sensory placode, is identified by a unique set of molecular markers (see also below), is the only region competent to respond to placode inducing signals and cells within it share the same developmental potential.

\section{Protecting sensory progenitors from inhibitory signals: PPR-inducing tissues and signals}

In chick, ablation and transplantation experiments have identified the mesoderm underlying the PPR as the source of PPR inducing signals, although there may also be some contribution from the adjacent neural plate, like in Xenopus. Ablation of the future heart mesoderm at head process stages - around the onset of PPR- 
specific gene expression - leads to the loss of Eya2 and Six4, while removal of the prechordal mesendoderm results in loss of Eya2 as well as the anterior PPR genes Pax6 and Nociceptin ( $p N o c$ ) (Litsiou et al., 2005; Lleras-Forero et al., 2013). When transplanted next to PPR-competent epiblast of the area opaca, each tissue can induce a full set of PPR markers, but also provides regional information (Hintze et al., 2017, Litsiou et al., 2005): future heart mesoderm generates sensory progenitors with posterior character expressing e.g. Foxi3, Gbx2 and Irx2, while prechordal mesendoderm promotes anterior identity (Otx2+, Hesx1+, SSTR5+, pNoc+, Six3+). In contrast, the neural plate does not induce a full complement of PPR transcripts and therefore alone is not sufficient to impart sensory progenitor identity to non-placodal cells (Hintze et al., 2017, Litsiou et al., 2005).

A recent molecular screen has identified a large number of genes that are activated in response to the heart mesoderm, many of which are also enriched in the PPR (Hintze et al., 2017; Lleras-Forero et al., 2013). These genes may act together, in parallel and/or upstream of the Six and Eya network. To explore the molecular events during PPR induction and to identify new upstream regulators of Six1 and Eya2, this study investigated the response of competent, non-placodal cells to mesoderm over time (Hintze et al., 2017). Heart mesoderm or prechordal mesendoderm was grafted next to competent area opaca epiblast. The tissue exposed to mesoderm signals and the contralateral control side were then collected 3, 6 and 12 hours later, and changes in gene expression were quantified using a NanoString probe set containing more than 100 genes including known and new PPR transcripts, markers for different placodes and for neural and neural crest cells. Surprisingly, this analysis reveals that although both tissues ultimately induce PPR with distinct regional character, they initially promote the expression of an identical set of transcription factors (see below for details), while repressing transcripts characteristic for the non-neural ectoderm and/or future epidermis (Hintze et al., 2017). This is rapidly followed by the induction of a second tier of factors, prior the induction of Six1 and Eya2 together with some of their known regulators. It is during the second phase of PPR induction that prechordal mesendoderm and heart mesoderm induced tissues begin to diverge, and 12 hours after exposure distinct anterior and posterior identity is established (Hintze et al., 2017). Thus, this new model suggests that during PPR induction cells initially adopt a common transcriptional state before they gradually diversify to generate sensory progenitors with anterior and posterior character.

FGF activation together with BMP and Wnt inhibition have been implicated in the induction of sensory progenitors in chick, fish and frog (Ahrens and Schlosser, 2005, Brugmann et al., 2004, Litsiou et al., 2005). Members of these pathways are normally expressed in both PPR-inducing mesoderm populations, while BMP and Wnt ligands are present in surrounding tissues (Fig. 2). In chick, FGF8 partially mimics the activity of the future heart mesoderm and prechordal mesendoderm: FGF8 beads induce most of the early response genes in area opaca epiblast (Hintze et al., 2017, Litsiou et al., 2005). In contrast, when mesoderm is grafted together with the FGF pathway inhibitor SU5402, their induction is diminished. However, when SU402 beads are added 5 hours after cells have been exposed to mesodermal signals PPR induction continues normally (Litsiou et al., 2005). Thus, FGF signalling is required during PPR initiation, but is dispensable later. In contrast, BMP antagonism alone only induces very few genes, but is required
A
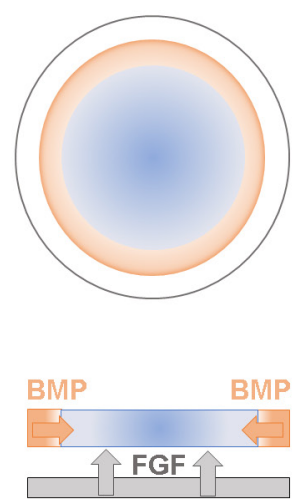

B
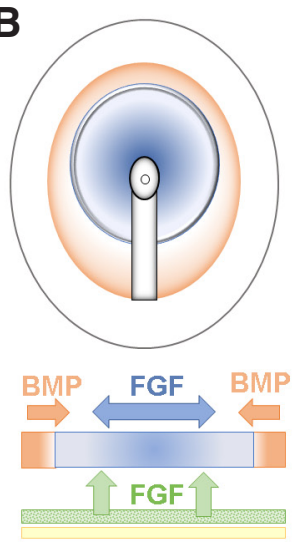

C

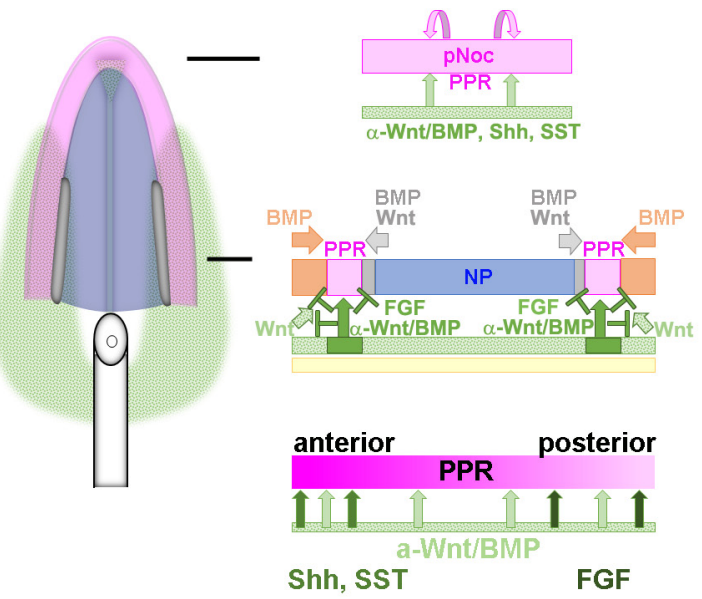

Fig. 2. Signals involved in the neural plate border and pre-placodal region (PPR). (A) At pre-streak stages the epiblast is roughly subdivided into a central domain (blue) expressing pre-neural genes, and in a peripheral territory (orange) expressing non-neural factors. However, there is considerable overlap in gene expression. Pre-neural genes can be induced by the hypoblast and many are FGF dependent, while non-neural genes are under the control of BMP signalling from the extraembryonic territory. (B) During gastrulation, gene expression of pre-neural genes is maintained in the central epiblast and at late gastrula stages Sox2, a marker for the neural plate, begins to be expressed surrounding the node. Non-neural gene expression is maintained in the peripheral epiblast. FGF signalling emanates from the underlying mesoderm, as well as the future neural plate, while BMPs continue to be expressed in the lateral epiblast. At the neural plate border, pre-neural and non-neural genes continue to overlap. (C) At head process stages, the PPR becomes molecularly distinct (pink) surrounding the neural plate (blue-grey). The lateral plate mesoderm including the future heart mesoderm (green) has emerged from the primitive streak and comes to underlie much of the PPR, while the prechordal mesendoderm at the tip of the notochord underlies that anterior PPR. The two top diagrams on the right summarise the signalling events at the level of the black lines that promote anterior (top) and posterior (middle) PPR formation. Note: PPR cells are surrounded by inhibitory signals, but protected by signals from the mesoderm. Bottom diagram shows signalling along the anterior-posterior axis. 
throughout the inductive process: when BMP4 is added to grafted mesoderm many PPR transcripts are reduced including both early (e.g. Trim24, N-myc) and late factors (e.g. Six1, Eya2) (Hintze et al., 2017). Conversely, when Smad6, which antagonises BMP signalling, is misexpressed in the embryo at gastrula stages PPR transcripts are expanded (Litsiou et al., 2005). These findings match corresponding experiments in amphibian and fish embryos (Ahrens and Schlosser, 2005, Brugmann et al., 2004, Esterberg and Fritz, 2009, Glavic et al., 2004, Kwon et al., 2010). Finally, Wnt antagonism does not seem to play a major role during early steps of PPR induction: in the induction assay, none of the mesoderm induced genes are regulated by Wnt manipulation (Hintze et al., 2017). However, Wnt activation by misexpression of constitutively active $\beta$-catenin at gastrula stages leads to loss of PPR specific genes, while neural crest markers are expanded (Litsiou et al., 2005). Conversely, Wnt inhibition using crescent results in PPR expansion at the expense of neural crest (Litsiou et al., 2005). These observations suggest that while low levels of Wnt may be required for PPR specification, Wnt signalling is mainly responsible for the segregation of placode and neural crest precursors at later stages. In summary, at head fold stages sensory progenitor cells in the PPR are surrounded by inhibitory signals: BMPs and Wnts from the future neural crest and the future epidermis, as well as Wnt ligands from the lateral and posterior mesoderm (Fig. 2C). FGF in combination with Wnt and BMP antagonists from the heart mesoderm and the prechordal mesendoderm protect the PPR from these inhibitory influences and thus allow its specification next to the anterior neural plate.

While these signals mediate generic PPR induction they do not account for the regional bias imparted by each mesodermal population. The anterior mesendoderm expresses high levels of sonichedgehog (Shh). Indeed, combining prechordal mesendoderm grafts with the Shh inhibitor cyclopamine prevents the induction of anterior (Six3, Otx2), but not generic PPR factors (Six1, Eya2) (Hintze et al., 2017). Thus, Shh is at least in part responsible for imparting anterior character to sensory progenitors (Fig. 2C). The mesendoderm also expresses the neuropeptide somatostatin and somatostatin-coated beads are sufficient to restore anterior marker expression (Pax6, pNoc) after mesendoderm ablation suggesting that it cooperates with Shh (Lleras-Forero et al., 2013). The aPPR itself expresses $p N o c$, another neuropeptide, required for anterior identity. pNoc inhibition using pharmacological inhibitors or knock down of its receptor SSTR5 results in the loss of anterior markers like Pax6 and pNoc itself (Lleras-Forero, 2013). Thus, while Shh and somatostatin participate in anterior PPR induction by the mesendoderm, pNoc seems to act in an autocrine fashion to maintain anterior PPR character once induced (Fig. 2C).

\section{A transcription factor hierarchy upstream of the Six- Eya network}

Members of the Six and Eya families of nuclear factors lie at the heart of sensory progenitor specification. They act as a complex to activate downstream target genes (for review, see: Xu, 2013; Jemc, 2007; Kawakami, 2000; Donner, 2004; Hanson, 2001), but also promote their own expression and that of other PPR genes (Brugmann et al., 2004; Christophorou et al., 2009). Thus, once expressed they may maintain cells in a placode progenitor state (for review, see: Grocott et al., 2012). What is the transcriptional input that regulates the expression of Six1 and Eya2 in the PPR? The molecular screen described above has identified many new factors that may act in parallel, together and/or upstream of the Six and Eya network, while the time course analysis of mesoderm response genes establishes the sequence of their activation during the induction process.

In response to mesodermal signals competent epiblast rapidly upregulates of a small set of known or putative transcription factors (Cited2, ERNI, Etv5, Otx2, Trim24, Znf462, Mynn), while repressing others (DIx3/5, Gata2, Msx1, Tfap2a) (Hintze et al., 2017). The latter are generally considered to be non-neural or future epidermal markers (Hoffman, 2007, Knight et al., 2003, McLarren et al., 2003, Papalopulu and Kintner, 1993, Pera and Kessel, 1999, Pera et al., 1999, Phillips et al., 2006, Pieper et al., 2012, Sheng and Stern, 1999, Streit and Stern, 1999, Suzuki et al., 1997, Woda et al., 2003, Yang et al., 1998), while the former are later expressed in neural and placodal tissues and have been termed 'pre-neural' factors (Albazerchi and Stern, 2007; Bally-Cuif et al., 1995; Pinho et al., 2011; Rex et al., 1997; Streit et al., 2000; Trevers et al., 2017; for review, see: Grocott et al., 2012; Stern and Downs, 2012). During normal development, these genes are already expressed at prestreak stages, with the induced transcripts being widespread in the central epiblast, and repressed genes confined to the periphery (Trevers et al., 2017). However, the expression patterns of both groups overlap considerably (for review, see Grocott et al., 2012). Most pre-neural genes are activated by FGF signalling, although Otx2 also requires Wnt and BMP antagonists (Albazerchi and Stern, 2007; Hintze et al., 2017; Streit et al., 2000; Wilson et al., 2000). In chick, these signals emanate from the hypoblast, an extraembryonic tissue equivalent to the anterior visceral endoderm in mouse, and indeed hypoblast grafts can mimic the initial step of PPR induction: when hypoblast is grafted into the area opaca it rapidly upregulates the same genes that are induced by mesoderm (Albazerchi and Stern, 2007; Hintze et al., 2017; Streit et al., 2000; Trevers et al., 2017). In contrast, hypoblast and mesodermal signals repress non-neural transcripts, and this depends on activation of FGF signalling and BMP inhibition (Hintze et al., 2017; Trevers et al., 2017). For example, repression of non-neural genes by the mesoderm is overcome by supplying extra BMP4 (Hintze et al., 2017). Indeed, BMP4 and -7 are strongly expressed in the area opaca (Chapman et al., 2002, Streit et al., 1998), and thus present at the right time and in the right place to promote the expression of non-neural transcripts. Thus, at pre-streak stages signals from surrounding tissues (hypoblast and extraembryonic region) begin to subdivide the epiblast into 'non-neural' and 'pre-neural'territories although there is considerable overlap between both territories.

The second tier of mesoderm-induced factors largely consist of molecules previously not associated with PPR formation, but network inference approaches identify them as putative targets of the early 'pre-neural' genes (Hintze et al., 2017). Like pre-neural genes, they are already expressed before gastrulation (Trevers et al., 2017). Among them the zinc-finger factor Znf462 is predicted to be a hub, where inputs from all 'pre-neural'factors converge. Indeed, knock-down of Znf462 using morpholinos reveals that this factor is required for Foxi3, Gata3, Dlx6 and Gbx2 (Hintze et al., 2017), all of which are known to regulate Six1 and/or Eya2 (Esterberg and Fritz, 2009, Kwon et al., 2010, Luo et al., 2001, McLarren et al., 2003, Pieper et al., 2012, Sato et al., 2010, Solomon and Fritz, 2002, Woda et al., 2003). Accordingly, Six1 and Eya2 expression 
are lost in the absence of Znf462. The Lim domain factor Pdlim4 appears to be repressed by Znf462; Pdlim4 provides positive input for DIx6 and is required for Six1 and Eya2 (Hintze et al., 2017). Thus, Znf462 emerges as a new key regulator in the PPR gene network. Like the 'pre-neural' genes, many of the second-tier factors are also regulated by FGF signalling, and/or require BMP antagonism as shown by grafting experiments together with pathway agonists or antagonists similar to the experiments described above (Hintze et al., 2017).

As the embryo undergoes gastrulation, both $1^{\text {st }}$ and $2^{\text {nd }}$ tier factors are maintained in the future neural plate and its border, labelling progenitors for the entire central and peripheral nervous system (Hintze et al., 2017). However, at the neural plate border (NPB) they continue to overlap with many non-neural genes although the latter begin to segregate to form molecularly distinct subdomains. At late gastrula stages, the neural marker Sox2 begins to be expressed close to the organiser (Papanayotou et al., 2008, Rex et al., 1997). While Foxi3 and members of the Tfap2 and D/x families directly abut the Sox $2^{+}$domain, Gata2/3 do not, but are expressed slightly more lateral. Thus, just prior to PPR formation and the onset of Six/Eya genes, the ectoderm is subdivided into four molecularly distinct domains: the central epiblast where $1^{\text {st }}$ and $2^{\text {nd }}$ tier factors overlap with the neural marker Sox2, the 'inner NPB' where these transcripts overlap with DIx, Tfap2 and Foxi factors, the 'outer NPB' where Gata2/3 are also present, and finally the non-neural ectoderm expressing only non-neural genes (see (Grocott et al., 2012 and references therein). Around the onset of Six1 and Eya2 expression, individual NPB cells co-express neural, neural crest and sensory progenitor markers in different combinations suggesting that they may have the potential to develop into these lineages (see below) (Roellig et al., 2017).

These spatial and temporal changes in gene expression as the embryo develops from pre-streak to late gastrulation changes, matches the sequence of events observed in the PPR induction assay. In the final step, the induction of the Six/Eya cassette by mesoderm-derived signals is accompanied by the initiation of factors known to regulate their expression in chick and frog. Among them are Foxi3, Sall1, Gata3, Gbx2 and Hey1, as well as genes that were repressed by mesodermal signals like DIx6and Tfap2a at earlier time points (Hintze et al., 2017). Although this has not been explored in detail in chick, experiments in Xenopus and zebrafish suggest a complex regulatory relationship among Gata2/3, Tfap2, DIx and Foxi1 factors (Kwon et al., 2010, Pieper et al., 2012). In frog, Foxi1a overexpression promotes the expression of D/x3, which in turn is required for Foxi1a. In addition, DIx3 and Gata2 control their own expression and that of $D / x 5$, while in fish Gata3 and $A p 2$ are required for $D / x 3$. Misexpression of any of these factors prevents neural plate formation, suggesting that a major function of these proteins is to restrict neural plate expansion. Experiments in chick have confirmed some of these regulatory relationships: DIx5 misexpression not only represses neural and neural crest genes, but activates Foxi3, which in turn promotes DIx5 (Khatri et al., 2014, McLarren et al., 2003). Thus, once non-neural genes are expressed positive feedback loops reinforce their own expression and may make them independent from further signalling input.

Furthermore, these non-neural factors provide critical transcriptional input for the onset of Six1 and Eya2 at head process stages. Misexpression of DIx5 in chick and DIx3 in frog represses neural crest markers, while promoting PPR fate, while fish DIx3b and $-4 b$ mutants loose PPR gene expression Eya2 (Esterberg and Fritz, 2009, Luo et al., 2001, McLarren et al., 2003, Solomon and Fritz, 2002, Woda et al., 2003). In Xenopus, DIx3 is required for ectodermal cells to generate a PPR in response to FGF and BMP antagonists, and has therefore been implicated as 'competence factor' (Pieper et al., 2012). Indeed, evidence in chick shows that DIx5 directly regulates Six1: the Six1 enhancer element that drives its expression in the anterior PPR requires DIx5 activity (Sato et al., 2010). Together these findings suggest that DIx factors are important activators of the Six/Eya network. Using similar experimental strategies experiments in frog and fish have shown that Tfap2, Gata and Foxi transcription factors are cell autonomously required for the expression of Six and Eya genes: in their absence ectodermal cells are not competent to respond to PPR inducing signals and cannot activate Six/Eya factors (Kwon et al., 2010, Pieper et al., 2012). Finally, Foxi3 misexpression in chick is sufficient to activate ectopic expression of the PPR markers Six1 and Eya2 (Khatri et al., 2014). Whether this is occurs through direct binding of Foxi3 to the Six1 enhancer, or indirectly via DIx5 activation remains to be determined.

While the experiments described above provide evidence for activators of Six1 and/or Eya2, few factors have been implicated in their repression. During PPR induction, signals from the heart mesoderm or prechordal mesendoderm repress the expression of Msx1 (Hintze et al., 2017). At pre-streak stages Msx1 is expressed in the outer embryonic epiblast together with D/x5/6 and Gata2/3 (Pera et al., 1999, Sheng and Stern, 1999, Streit and Stern, 1999). During gastrulation, it is first seen in the epiblast next to the posterior primitive streak, and is then rapidly confined to a thin strip of cells along the border of the neural plate, the future neural crest, similar to Pax7 (Basch et al., 2006). Like Dlx5, Msx1 directly binds to the Six1-14 enhancer that is active in the PPR (Sato et al., 2010). However, while Dlx5 promotes its activity, misexpression of Msx1, as well as Pax7 abolishes enhancer activity completely (Sato et al., 2010). Thus, the expression of Six1 in sensory progenitors is tightly controlled through both positive and negative regulation. Moreover, while the Six1/Eya2 complex activates other PPR specific transcripts it also suppresses genes characteristic for alternative fates (Brugmann et al., 2004, Christophorou et al., 2009). Misexpression of Six1 and Eya2 results in the upregulation of PPR genes like Six4 and Sox11, as well as its upstream regulators Gata3 and DIx5. In contrast, Six1/Eya2 repress neural (Sox2, Sox3) and neural crest markers (Pax7).

In summary, recent experiments in chick have unravelled a transcription factor hierarchy upstream of the Six1/Eya2 network. The quantification of many newly identified genes together with the analysis of PPR induction over time, highlights the sequential activation of two cohorts of pre-neural genes that label progenitors for the entire nervous system, and the repression of non-neural genes. Among the pre-neural genes, the zinc-finger transcription factor Znf426 emerges as a new hub that integrates many upstream inputs, while regulating three of the four known PPR competence factors. As PPR induction progresses, non-neural genes are now activated; they promote their own expression as well as the activation of Six and Eya family members, while repressing neural fates. Once Six1 and Eya2 are expressed they not only activate other sensory progenitor genes, but also their own upstream regulators, which in turn prevent spreading of neural and neural crest factors. Thus, cross-repressive interactions among transcription factors that 
characterise progenitors for the neural, neural crest and placodal lineage together with positive feedback loops lead to sharpening of gene expression boundaries and ultimately segregation of different cell fates. Interestingly, individual cells at the NPB co-express neural, neural crest and placode factors suggesting that these interactions occur cell autonomously. Stochastic fluctuations in transcription factor levels may thus determine the ultimate fate of NPB cells. To unravel the mechanism single cell expression analysis combined with lineage tracing of cells with specific expression profiles will be required.

\section{Similarities in neural and sensory progenitor induction}

Many of the experiments described above take advantage of the fact that the extraembryonic epiblast in chick is competent to respond to PPR inducing signals, and can differentiate into placode progenitors and mature placodes when exposed to appropriate signals e.g. a tissue graft. This induction assay rapidly recapitulates the gradual specification of ectodermal cells as sensory progenitors, and has allowed the molecular dissection of this process (Hintze et al., 2017). Surprisingly, a molecular screen for potential upstream regulators of the Six/Eya network using this assay only identified a handful of PPR-restricted genes: most mesoderm-response genes are already expressed in the pre-streak epiblast, show wide-spread expression at primitive streak stages encompassing progenitors for the central and peripheral (crest and placodes) nervous system, and later become confined to the neural plate and PPR or to the neural plate alone (Hintze et al., 2017, Trevers et al., 2017). These observations point to a molecular similarity between early neural and sensory progenitor cells.

Neural induction can be initiated by a graft of the avian organiser, Hensen's node, into the extraembryonic area opaca (Waddington, 1932, Waddington, 1933), leading to the formation of a Sox2-expressing neural plate within 7 hours (Trevers et al., 2017). Analysis of transcripts upregulated 5 hours after a node graft reveals striking similarity with transcriptional profile initiated by PPR-inducing mesoderm, and to the transcriptional signature of pre-streak epiblast (Hintze et al., 2017, Trevers et al., 2017). Therefore, the initial steps in neural and PPR induction may be similar, if not identical, and resemble the gene expression profile in the pre-streak epiblast. Thus, cells may transit through a common transcriptional state before being committed to their respective lineage. This common state has been termed 'pre-border state', and has a transcriptional profile akin to mouse embryonic stem cell lines.

Interestingly, the transcriptional signature of sensory progenitors

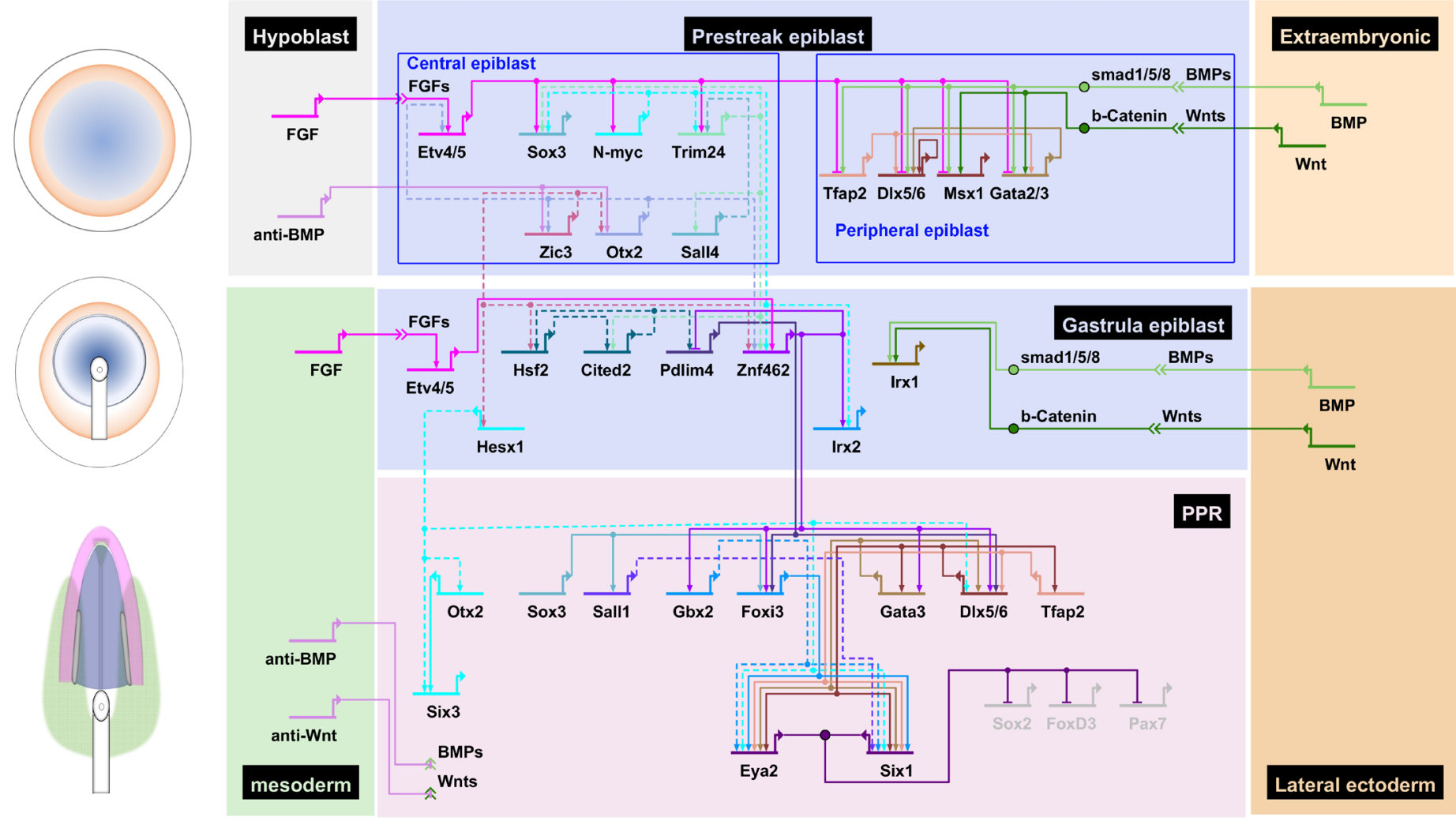

Fig. 3. Transcription factor network upstream of pre-placodal region (PPR) specifiers Six1 and Eya2. Signals and transcription factors are shown from pre-streak to headfold stages; diagrams on the left show the corresponding embryonic stages. In the network, regions are colour-coded like in the embryo diagrams. Signals from the hypoblast promote the expression of pre-neural genes in the central pre-streak epiblast, while signals from the extraembryonic region promote non-neural gene expression. At gastrula stages FGFs emanate from the mesoderm and promote a second tier of factors in the central epiblast, while BMP and Wnt signalling continue to enhance non-neural gene expression. PPR formation requires BMP and Wnt antagonism, and combination of pre-neural and non-neural factors promote the expression of Six1 and Eya2, which in turn repress neural (Sox2) and neural crest factors (Foxd3, Pax7). Genes in cyan (Hesx1, Otx2, Six3) are confined to the anterior PPR at head fold stages, and genes in sky blue (Irx2, Gbx2, Foxi3) are restricted to the posterior PPR. 
in the PPR is also similar to the pre-border state: using network inference algorithms combined with community clustering to analyse the transcriptome of pre-border (pre-streak epiblast +5 hours induced epiblast), neural plate and PPR cells from headfold stages, reveals a strong similarity between the PPR and pre-border state (Trevers et al., 2017). These observations suggest that PPR cells may retain some stem cell-like character of the pre-streak epiblast, prior to their differentiation into mature placodes. This finding is reminiscent of the observation that in Xenopus animal pole cells from the early blastula express pluripotency markers, and that these genes are retained by neural crest cells (BuitragoDelgado et al., 2015).

The above experiments indicate a surprising similarity in the initial response to neural and PPR inducing signals. If the induced transcriptional state is indeed identical it should be possible to initiate induction with any tissue, and then complete it with another, which then determines the final outcome. Agraft of Hensen's node takes 7 hours to induce Sox $2+$ neural tissue. However, when the extraembryonic epiblast is first primed by head mesoderm for 3 hours, the node only takes 4 hours to induce Sox2 (Trevers et al., 2017). Likewise, 3 hours exposure to a node primes the epiblast to respond more rapidly to mesoderm grafts and generate sensory progenitor specific gene expression (Trevers et al., 2017). Furthermore, the hypoblast also induces the pre-border state and can substitute for node or mesoderm within the first 3 hours of the induction process (Trevers et al., 2017). Together, these findings indicate that the epiblast responds to neural and PPR inducing tissues in the same manner by initiating a unique transcriptional response (pre-border). In normal development, this transcriptional profile resembles that of the pre-streak epiblast, which in turn may be induced by the underlying hypoblast. Thus, initiation of neural and sensory progenitor induction initially follows a similar programme and cell fates diverge later.

\section{Models for cell fate segregation at the neural plate border}

Experiments in Xenopus have previously suggested a 'dual competence model' to explain the segregation of neural, neural crest, placodal and epidermal lineages (Pieper et al., 2012) for review: (Schlosser, 2008). Based on a series of transplantation experiments, the model proposes that changes in competence divide the ectoderm into two territories, one competent to give rise to neural and neural crest cells, versus another competent to generate sensory placodes and epidermis. When the neural plate from neurula stage embryos is transplanted into the crest or placode territory, it can be induced to generate neural crest cells, but not placodes. When the same experiment is performed with future epidermis, the epidermis can generate placodes, but no neural crest cells. This led to the conclusion that restriction of competence initiates segregation of ectodermal lineages. This model differs from the neural plate border model (NPB model) in chick (for review: Grocott et al., 2012), which proposes that cell fates are gradually restricted over time, and that NBP cells retain the ability to generate neural, neural crest, placode and epidermal cells for some time and respond to local cues that drive them towards different fates.

The dual competence model implies that cells should lose competence to respond to neural and PPR-inducing signals at different times. However, in chick this is not the case: competence of the extraembryonic epiblast to generate neural tissue in response to an organiser graft and to produce PPR in response to head mesoderm is lost at exactly the same stage $\left(\mathrm{HH} 4^{+}\right)$(Litsiou, 2004, Litsiou et al., 2005, Storey et al., 1992). Furthermore, recent evidence indicates that both neural and PPR induction share common features with induced cells going through the same transcriptional state before they diversify (Trevers et al., 2017). These findings are compatible with the NPB model, but difficult to reconcile with the dual competence model.

In chick, the epiblast is gradually subdivided into domains with different gene expression profiles (see above). This begins before gastrulation where two broad territories can be distinguished, which do however, overlap considerably. As development proceeds new genes become expressed under the influence of local signals and gene expression boundaries gradually sharpen, but continue to overlap at the NPB. Sharpening of these boundaries is mediated by cross-repressive transcription factor interactions, and by positive feedback loops in which 'like' promotes 'like'. Indeed, the same changes in expression patterns are observed in Xenopus at blastula stages (Pieper et al., 2012), and experiments using gain- and loss-of-function of transcription factors suggest similar regulatory relationships. It is therefore likely that the mechanisms that segregate cell fates in the ectoderm in avian and amphibian embryos are very similar, or identical.

Recent evidence in chick reveals that NPB cells are indeed a special cell population where neural, neural crest and placode markers not only overlap, but also are co-expressed in the same cell (Roellig et al., 2017). Using antibodies for Sox2, Pax7 and Six1, proteins generally considered to be specific for neural, neural crest and placode progenitor cells, this study reveals that NBP cells are heterogeneous expressing different combinations and levels of these factors. This heterogeneity is apparent at gastrula stages and persists in the neural folds and in the non-neural ectoderm until at least the 10-somite. Lineage tracing Sox $2^{+}$cells reveals that they continue to generate neural crest cells even at neural fold stages, and this is consistent with previous single cell labelling studies in chick and mouse (Baggiolini et al., 2015, Bronner-Fraser and Fraser, 1988, McKinney et al., 2013). Using misexpression and knockdowns this study shows that different levels of Sox 2 and Pax7 drive cells towards neural and neural crest lineages, respectively. These findings are incompatible with the dual competence model, and the most parsimonious explanation is that cells in the NBP have the potential to generate multiple fates, and that this property is maintained long after neural plate formation. Thus, NBP cells appear to be unique multipotent progenitors for the entire nervous system and future studies involving single cell analysis combined with lineage tracing will be required to unravel the molecular mechanisms that control their commitment to a single lineage.

\section{Concluding remarks}

Placode progenitors give rise to much of the peripheral nervous system in the vertebrate head, and arise together with neural crest cells in the ectoderm surrounding the neural plate. Recent studies in chick have called existing models for cell fate segregation in the ectoderm into question, which suggest that the neural plate border is subdivided into distinct domains of different progenitors. In contrast, it turns out that neural plate border cells are heterogeneous with individual cells expressing different combinations 
and levels of transcription factors previously thought to be neural, crest and placode 'specifiers'. This heterogeneity and cell mixing persists until the time of neural tube closure suggesting neural plate border cells are open for different fates much longer than previously thought. The discovery of an unexpected similarity between neural, neural crest and placode induction agrees with these findings, and the identification of many new potential players and their assembly into a new predictive network, provide a new framework to explore lineage segregation at the neural plate border with a new perspective.

\section{References}

AHRENS, K. and SCHLOSSER, G. (2005). Tissues and signals involved in the induction of placodal Six1 expression in Xenopus laevis. Dev Biol 288: 40-59.

ALBAZERCHI, A. and STERN, C.D. (2007). A role for the hypoblast (AVE) in the initiation of neural induction, independent of its ability to position the primitive streak. Dev Biol. 301: 489-503.

ANWAR, M., TAMBALO, M., RANGANATHAN, R., GROCOTT, T. and STREIT, A (2017). A gene network regulated by FGF signalling during ear development. Sci. Reports 7: 6162

BAGGiOLINI, A., VARUM, S., MATEOS, JOSÉ M., BETTOSINI, D., JOHN, N., BONALLI, M., ZIEGLER, U., DIMOU, L., CLEVERS, H., FURRER, R. et al., (2015). Premigratory and Migratory Neural Crest Cells Are Multipotent In Vivo. Cell Stem Cell 16: 314-322.

BAILEY, A.P., BHATTACHARYYA, S., BRONNER-FRASER, M. and STREIT, A. (2006). Lens specification is the ground state of all sensory placodes, from which FGF promotes olfactory identity. Dev Cell 11: 505-5017.

BAKER, C.V. and BRONNER-FRASER, M. (2001). Vertebrate cranial placodes I. Embryonic induction. Dev Biol 232: 1-61.

BAKER, C.V., STARK, M.R., MARCELLE, C. and BRONNER-FRASER, M. (1999). Competence, specification and induction of $\mathrm{Pax}-3$ in the trigeminal placode. Development 126: 147-156.

BALLY-CUIF, L., GULISANO, M., BROCCOLI, V. and BONCINELLI, E. (1995). c-otx2 is expressed in two different phases of gastrulation and is sensitive to retinoic acid treatment in chick embryo. Mech Dev 49: 49-63.

BASCH, M.L., BRONNER-FRASER, M. and GARCIA-CASTRO, M.I. (2006). Specification of the neural crest occurs during gastrulation and requires Pax7. Nature 441: 218-222

BEARD, J. (1886). The system of brancial sense organs and their associated ganlia in Ichthyopsida. A contribution to the ancestral history of Vertebrates. Q. J. Microsc. Sci. 26: 95-156.

BESSARAB, D.A., CHONG, S.W. and KORZH, V. (2004). Expression of zebrafish six1 during sensory organ development and myogenesis. Dev Dyn 230: 781-776.

BHAT, N. and RILEY, B.B. (2011). Integrin-alpha5 coordinates assembly of posterior cranial placodes in zebrafish and enhances Fgf-dependent regulation of otic/ epibranchial cells. PLOS ONE 6: e27778.

BHATTACHARYYA, S., BAILEY, A.P., BRONNER-FRASER, M. and STREIT, A. (2004). Segregation of lens and olfactory precursors from a common territory: cell sorting and reciprocity of DIx5 and Pax6 expression. Dev Biol 271: 403-414.

BHATTACHARYYA, S. and BRONNER-FRASER, M. (2008). Competence, specification and commitment to an olfactory placode fate. Development 135: 4165-4177.

BRONNER-FRASER, M. and FRASER, S.E. (1988). Cell lineage analysis reveals multipotency of some avian neural crest cells. Nature 335: 161-164.

BRUGMANN, S.A., PANDUR, P.D., KENYON, K.L., PIGNONI, F. and MOODY, S.A (2004). Six1 promotes a placodal fate within the lateral neurogenic ectoderm by functioning as both a transcriptional activator and repressor. Development 131: $5871-5881$.

BUITRAGO-DELGADO, E., NORDIN, K., RAO, A., GEARY, L. and LABONNE, C. (2015). NEURODEVELOPMENT. Shared regulatory programs suggest retention of blastula-stage potential in neural crest cells. Science 348: 1332-1335.

CANNING, C.A., LEE, L., LUO, S.X., GRAHAM, A. and JONES, C.M. (2008). Neural tube derived Wnt signals cooperate with FGF signaling in the formation and differentiation of the trigeminal placodes. Neural Dev 3: 35.
CHAPMAN, S.C., SCHUBERT, F.R., SCHOENWOLF, G.C. and LUMSDEN, A. (2002) Analysis of spatial and temporal gene expression patterns in blastula and gastrula stage chick embryos. Dev Biol 245: 187-199.

CHEN, J., TAMBALO, M., BAREMBAUM, M., RANGANATHAN, R., SIMOES-COSTA M., BRONNER, M.E. and STREIT, A. (2017). A systems-level approach reveals new gene regulatory modules in the developing ear. Development 144:1531-1543.

CHRISTOPHOROU, N.A., BAILEY, A.P., HANSON, S. and STREIT, A. (2009). Activation of Six 1 target genes is required for sensory placode formation. Dev Biol 336: 327-336

COULY, G. and LE DOUARIN, N.M. (1988). The fate map of the cephalic neural primordium at the presomitic to the 3-somite stage in the avian embryo. Development 103: 101-113.

COULY, G.F. and LE DOUARIN, N.M. (1985). Mapping of the early neural primordium in quail-chick chimeras. I. Developmental relationships between placodes, facial ectoderm, and prosencephalon. Dev Biol 110: 422-439.

COULY, G.F. and LE DOUARIN, N.M. (1987). Mapping of the early neural primordium in quail-chick chimeras. II. The prosencephalic neural plate and neural folds: implications for the genesis of cephalic human congenital abnormalities. Dev Biol 120: 198-214.

D'AMICO-MARTEL, A. and NODEN, D.M. (1980). An autoradiographic analysis of the development of the chick trigeminal ganglion. J Embryol Exp Morphol55: 167-182.

D'AMICO-MARTEL, A. and NODEN, D.M. (1983). Contributions of placodal and neural crest cells to avian cranial peripheral ganglia. Am J Anat 166: 445-468.

DONNER, A.L. and MAAS, R.L. (2004). Conservation and non-conservation of genetic pathways in eye specification. Int $J$ Dev Biol 48: 743-753.

DUTTA, S., DIETRICH, J.E., ASPOCK, G., BURDINE, R.D., SCHIER, A., WESTERFIELD, M. and VARGA, Z.M. (2005). pitx3 defines an equivalence domain for lens and anterior pituitary placode. Development1579-1590.

ESTERBERG, R. and FRITZ, A. (2009). dlx3b/4b are required for the formation of the preplacodal region and otic placode through local modulation of BMP activity. Dev Biol 325: 189-199.

ESTEVE, P. and BOVOLENTA, P. (1999). cSix4, a member of the six gene family of transcription factors, is expressed during placode and somite development. Mech Dev 85: 161-165.

FRETER, S., MUTA, Y., MAK, S.S., RINKWITZ, S. and LADHER, R.K. (2008). Progressive restriction of otic fate: the role of FGF and Wnt in resolving inner ear potential. Development 135: 3415-3424.

FRORIEP,A. (1885). UberAnlagen von Sinnesorganen am Facialis, Glossopharyngeus und Vagus, ueber die genetische Stellung des Vagus zum Hypoglossus, und ueber die Herkunft der Zungenmusculatur. Arch. Anat. Physiol. 5: 1-55.

GLAVIC, A., MARIS HONORE, S., GLORIA FEIJOO, C., BASTIDAS, F., ALLENDE, M.L. and MAYOR, R. (2004). Role of BMP signaling and the homeoprotein Iroquois in the specification of the cranial placodal field. Dev Biol 272: 89-103.

GROCOTT, T., TAMBALO, M. and STREIT, A. (2012). The peripheral sensory nervous system in the vertebrate head: A gene regulatory perspective. Dev Bio/370: 3-23.

GROVES, A.K. and BRONNER-FRASER, M. (2000). Competence, specification and commitment in otic placode induction. Development 127: 3489-3499.

HANSON, I.M. (2001). Mammalian homologues of the Drosophila eye specification genes. Semin Cell Dev Biol 12: 475-484.

HINTZE, M., PRAJAPATI, R.S., TAMBALO, M., CHRISTOPHOROU, N.A.D., ANWAR, M., GROCOTT, T. and STREIT, A. (2017). Cell interactions, signals and transcriptional hierarchy governing placode progenitor induction. Development 144: $2810-2823$

HOFFMAN, T.L., ANNA L. JAVIER, SHELLEY A. CAMPEAU, ROBERT D. KNIGHT, THOMAS F. SCHILLING,. (2007). Tfap2 transcription factors in zebrafish neura crest development and ectodermal evolution. J. Exp. Zool. Part B: Molec. Dev. Evol. 308B: 679-691

ISHIHARA, T., SATO, S., IKEDA, K., YAJIMA, H. and KAWAKAMI, K. (2008). Multiple evolutionarily conserved enhancers control expression of Eya1. Dev Dyn 237: 3142-3156.

JACOBSON, A. (1963a). The determination and positioning of the nose, lens and ear. J Exp Zool 154: 273-303

JACOBSON, A.G. (1963b). The determination and positioning of the nose, lens, and ear. III. Effects of reversing the antero-posterior axis of epidermis, neural plate and neural fold. J Exp Zool 154: 293-303. 
JEMC, J. and REBAY, I. (2007). The eyes absent family of phosphotyrosine phosphatases: properties and roles in developmental regulation of transcription. Annu Rev Biochem 76: 513-538.

KAWAKAMI, K., SATO, S., OZAKI, H. and IKEDA, K. (2000). Six family genes-structure and function as transcription factors and their roles in development. Bioessays 22: 616-626.

KENYON, K.L., LI, D.J., CLOUSER, C., TRAN, S. and PIGNONI, F. (2005). Fly SIXtype homeodomain proteins Sine oculis and Optix partner with different cofactors during eye development. Dev Dyn 234: 497-504.

KHATRI, S.B., EDLUND, R.K. and GROVES, A.K. (2014). Foxi3 is necessary for the induction of the chick otic placode in response to FGF signaling. Dev Biol 391: 158-169.

KNIGHT, R.D., NAIR, S., NELSON, S.S., AFSHAR, A., JAVIDAN, Y., GEISLER, R., RAUCH, G.J. and SCHILLING, T.F. (2003). lockjaw encodes a zebrafish tfap2a required for early neural crest development. Development 130: 5755-5768.

KNOUFF, R.A. (1935). The developmental pattern of ectodermal placodes in Rana pipiens. J. Comp. Neurol. 62: 17-71.

KOBAYASHI, M., NISHIKAWA, K., SUZUKI, T. and YAMAMOTO, M. (2001). The homeobox protein Six3 interacts with the Groucho corepressor and acts as a transcriptional repressor in eye and forebrain formation. Dev Biol 232: 315-326.

KOBAYASHI, M., OSANAI, H., KAWAKAMI, K. and YAMAMOTO, M. (2000). Expression of three zebrafish Six4 genes in the cranial sensory placodes and the developing somites. Mech Dev 98: 151-155.

KOZLOWSKI, D.J., MURAKAMI, T., HO, R.K. and WEINBERG, E.S. (1997). Regional cell movement and tissue patterning in the zebrafish embryo revealed by fate mapping with caged fluorescein. Biochem Cell Biol 75: 551-562.

KWON, H.J., BHAT, N., SWEET, E.M., CORNELL, R.A. and RILEY, B.B. (2010). Identification of early requirements for preplacodal ectoderm and sensory organ development. PLoS Genet 6.

LADHER, R.K., ANAKWE, K.U., GURNEY,A.L., SCHOENWOLF, G.C. and FRANCISWEST, P.H. (2000). Identification of synergistic signals initiating inner ear development. Science 290: 1965-1968.

LI, X., OGHI, K.A., ZHANG, J., KRONES, A., BUSH, K.T., GLASS, C.K., NIGAM, S.K., AGGARWAL, A.K., MAAS, R., ROSE, D.W. et al., (2003). Eya protein phosphatase activity regulates Six1-Dach-Eya transcriptional effects in mammalian organogenesis. Nature 426: 247-254.

LITSIOU, A. (2004). Early development of cranial sensory placodes. PhD thesis, Kings College London (UK).

LITSIOU, A., HANSON, S. and STREIT, A. (2005). A balance of FGF, Wnt and BMP signalling positions the future placode territory in the head. Development 132: 4051-4062.

LLERAS-FORERO, L., CHRISTOPHOROU, N., CHAMBERS, D., HOUART, C. and STREIT, A. (2013). Neuropeptides: developmental signals in placode progenitor formation. Dev. Cell 26: 195-203.

LUO, T., MATSUO-TAKASAKI, M. and SARGENT, T.D. (2001). Distinct roles for Distalless genes DIx3 and DIx5 in regulating ectodermal development in Xenopus. $\mathrm{Mol}$ Reprod Dev 60: 331-337.

MAROON, H., WALSHE, J., MAHMOOD, R., KIEFER, P., DICKSON, C. and MASON, I. (2002). Fgf3 and Fgf8 are required together for formation of the otic placode and vesicle. Development 129: 2099-2108.

MARTIN, K. and GROVES, A.K. (2006). Competence of cranial ectoderm to respond to Fgf signaling suggests a two-step model of otic placode induction. Development 133: 877-887.

MCKINNEY, M.C., FUKATSU, K., MORRISON, J., MCLENNAN, R., BRONNER, M.E. and KULESA, P.M. (2013). Evidence for dynamic rearrangements but lack of fate or position restrictions in premigratory avian trunk neural crest. Development 140: 820-830

MCLARREN, K.W., LITSIOU, A. and STREIT, A. (2003). DLX5 positions the neura crest and preplacode region at the border of the neural plate. Dev Biol 259: 34-47.

MISHIMA, N. and TOMAREV, S. (1998). Chicken Eyes absent 2 gene: isolation and expression pattern during development. Int J Dev Biol 42: 1109-1115.

NECHIPORUK, A., LINBO, T., POSS, K.D. and RAIBLE, D.W. (2007). Specification of epibranchial placodes in zebrafish. Development 134: 611-623.

NECHIPORUK, A., LINBO, T. and RAIBLE, D.W. (2005). Endoderm-derived Fgf3 is necessary and sufficient for inducing neurogenesis in the epibranchial placodes in zebrafish. Development 132: 3717-3730

NIKAIDO, M., DOI, K., SHIMIZU, T., HIBI, M., KIKUCHI, Y. and YAMASU, K. (2007) Initial specification of the epibranchial placode in zebrafish embryos depends on the fibroblast growth factor signal. Dev Dyn 236: 564-571.

NODEN, D.M. (1992). Vertebrate craniofacial development: novel approaches and new dilemmas. Curr Opin Genet Dev 2: 576-881.

O'NEILL, P., MAK, S.S., FRITZSCH, B., LADHER, R.K. and BAKER, C.V. (2012). The amniote paratympanic organ develops from a previously undiscovered sensory placode. Nat Commun 3: 1041

OHTO, H., KAMADA, S., TAGO, K., TOMINAGA, S.I., OZAKI, H., SATO, S. and KAWAKAMI, K. (1999). Cooperation of six and eya in activation of their target genes through nuclear translocation of Eya. Mol Cell Biol 19: 6815-6824.

PANDUR, P.D. and MOODY, S.A. (2000). Xenopus Six1 gene is expressed in neurogenic cranial placodes and maintained in the differentiating lateral lines. Mech Dev 96: 253-257.

PAPALOPULU, N. and KINTNER, C. (1993). Xenopus Distal-less related homeobox genes are expressed in the developing forebrain and are induced by planar signals. Development 117: 961-975.

PAPANAYOTOU, C., MEY, A., BIROT, A.M., SAKA, Y., BOAST, S., SMITH, J.C. SAMARUT, J. and STERN, C.D. (2008). A mechanism regulating the onset of Sox2 expression in the embryonic neural plate. PLoS Biol 6: e2.

PATRICK, A.N., CABRERA, J.H., SMITH, A.L., CHEN, X.S., FORD, H.L. and ZHAO, R. (2013). Structure-function analyses of the human SIX1-EYA2 complex revea insights into metastasis and BOR syndrome. Nat Struct Mol Biol 20: 447-453.

PERA, E. and KESSEL, M. (1999). Expression of DLX3 in chick embryos. Mech Dev 89: 189-193.

PERA, E., STEIN, S. and KESSEL, M. (1999). Ectodermal patterning in the avian embryo: epidermis versus neural plate. Development 126: 63-73.

PHILLIPS, B.T., BOLDING, K. and RILEY, B.B. (2001). Zebrafish fgf3 and fgf8 encode redundant functions required for otic placode induction. Dev Biol 235: 351-365.

PHILLIPS, B.T., KWON, H.J., MELTON, C., HOUGHTALING, P., FRITZ, A. and RILEY, B.B. (2006). Zebrafish msxB, msxC and msxE function together to refine the neural-nonneural border and regulate cranial placodes and neural crest development. Dev Biol 294: 376-390.

PIEPER, M., AHRENS, K., RINK, E., PETER, A. and SCHLOSSER, G. (2012). Differential distribution of competence for panplacodal and neural crest induction to non-neural and neural ectoderm. Development 139: 1175-1187.

PIEPER, M., EAGLESON, G.W., WOSNIOK, W. and SCHLOSSER, G. (2011). Origin and segregation of cranial placodes in Xenopus laevis. Dev Biol 360: 257-275.

PIGNONI, F., HU, B., ZAVITZ, K.H., XIAO, J., GARRITY, P.A. and ZIPURSKY, S.L. (1997). The eye-specification proteins So and Eya form a complex and regulate multiple steps in Drosophila eye development [published erratum appears in Cell 1998 Feb 20;92(4):following 585]. Cell 91: 881-891.

PINHO, S., SIMONSSON, P.R., TREVERS, K.E., STOWER, M.J., SHERLOCK, W.T., KHAN, M., STREIT, A., SHENG, G. and STERN, C.D. (2011). Distinct steps of neural induction revealed by Asterix, Obelix and TrkC, genes induced by different signals from the organizer. PLOS ONE 6: e19157.

RAYAPUREDDI, J.P., KATTAMURI, C., STEINMETZ, B.D., FRANKFORT, B.J., OSTRIN, E.J., MARDON, G. and HEGDE, R.S. (2003). Eyes absent represents a class of protein tyrosine phosphatases. Nature 426: 295-298

REX, M., ORME, A., UWANOGHO, D., TOINTON, K., WIGMORE, P.M., SHARPE, P.T. and SCOTTING, P.J. (1997). Dynamic expression of chicken Sox2 and Sox3 genes in ectoderm induced to form neural tissue. Dev Dyn 209: 323-332.

ROELLIG, D., TAN-CABUGAO, J., ESAIAN, S. and BRONNER, M.E. (2017). Dynamic transcriptional signature and cell fate analysis reveals plasticity of individual neural plate border cells. Elife 6: e21620

SAINT-JEANNET, J.P. and MOODY, S.A. (2014). Establishing the pre-placodal region and breaking it into placodes with distinct identities. Dev Biol 389: 13-27.

SANCHEZ-ARRONES, L., SANDONIS, A., CARDOZO, M.J. and BOVOLENTA, P. (2017). Adenohypophysis placodal precursors exhibit distinctive features within the rostral preplacodal ectoderm. Development 144: 3521-3532.

SATO, S., IKEDA, K., SHIOI, G., OCHI, H., OGINO, H., YAJIMA, H. and KAWAKAMI K. (2010). Conserved expression of mouse Six1 in the pre-placodal region (PPR) and identification of an enhancer for the rostral PPR. Dev Biol 344: 158-171. 
SCHLOSSER, G. (2006). Induction and specification of cranial placodes. Dev Biol 294: 303-351.

SCHLOSSER, G. (2008). Do vertebrate neural crest and cranial placodes have a common evolutionary origin? Bioessays 30: 659-672.

SCHLOSSER, G. (2010). Making senses development of vertebrate cranial placodes. Int Rev Cell Mol Biol 283: 129-234.

SCHLOSSER, G. (2014). Development and evolution of vertebrate cranial placodes. Dev Biol 389: 1.

SHENG, G. and STERN, C.D. (1999). Gata2 and Gata3: novel markers for early embryonic polarity and for non-neural ectoderm in the chick embryo. Mech Dev 87: 213-216.

SOLOMON, K.S. and FRITZ, A. (2002). Concerted action of two dlx paralogs in sensory placode formation. Development 129: 3127-3136.

STERN, C.D. and DOWNS, K.M. (2012). The hypoblast (visceral endoderm): an evo-devo perspective. Development 139: 1059-1069.

STEVENTON, B., MAYOR, R. and STREIT, A. (2016). Directional cell movements downstream of Gbx2 and Otx2 control the assembly of sensory placodes. Biol Open 5: 1620-1624.

STOREY, K.G., CROSSLEY, J.M., DE ROBERTIS, E.M., NORRIS, W.E. and STERN, C.D. (1992). Neural induction and regionalisation in the chick embryo. Development 114: 729-741.

STREIT, A. (2002). Extensive cell movements accompany formation of the otic placode. Dev Biol 249: 237-254.

STREIT, A. (2007). The preplacodal region: an ectodermal domain with multipotential progenitors that contribute to sense organs and cranial sensory ganglia. Int $J$ Dev Biol 51: 447-461.

STREIT, A. (2008). The cranial sensory nervous system: specification of sensory progenitors and placodes. In Stembook, (ed. WATT, F. and GAGE, F.). The Stem Cell Research Community.

STREIT, A., BERLINER, A.J., PAPANAYOTOU, C., SIRULNIK, A. and STERN, C.D. (2000). Initiation of neural induction by FGF signalling before gastrulation. Nature 406: 74-78.

STREIT, A., LEE, K.J., WOO, I., ROBERTS, C., JESSELL, T.M. and STERN, C.D. (1998). Chordin regulates primitive streak development and the stability of induced neural cells, but is not sufficient for neural induction in the chick embryo. Development 125: 507-519.

STREIT, A. and STERN, C.D. (1999). Establishment and maintenance of the border of the neural plate in the chick: involvement of FGF and BMP activity. Mech Dev 82: 51-66.

SUN, S.K., DEE, C.T., TRIPATHI, V.B., RENGIFO, A., HIRST, C.S. and SCOTTING, P.J. (2007). Epibranchial and otic placodes are induced by a common Fgf signal, but their subsequent development is independent. Dev Biol 303: 675-686.
SUZUKI, A., UENO, N. and HEMMATI-BRIVANLOU, A. (1997). Xenopusmsx1 mediates epidermal induction and neural inhibition by BMP4. Development 124:3037-3044.

TESSMAR, K., LOOSLI, F. and WITTBRODT, J. (2002). A screen for co-factors of Six3. Mech Dev 117: 103-113.

THEVENEAU, E., STEVENTON, B., SCARPA, E., GARCIA, S., TREPAT, X., STREIT, A. and MAYOR, R. (2013). Chase-and-run between adjacent cell populations promotes directional collective migration. Nat Cell Biol 15: 763-772.

TOOTLE, T.L., SILVER, S.J., DAVIES, E.L., NEWMAN, V., LATEK, R.R., MILLS, I.A., SELENGUT, J.D., PARLIKAR, B.E. and REBAY, I. (2003). The transcription factor Eyes absent is a protein tyrosine phosphatase. Nature 426: 299-302.

TREVERS, K.E., PRAJAPATI, R.S., HINTZE, M., STOWER, M.J., STROBL, A.C., TAMBALO, M., RANGANATHAN, R., MONCAUT, N., KHAN, M.A.F., STERN, C.D. et al., (2017). Neural induction by the node and placode induction by head mesoderm share an initial state resembling neural plate border and ES cells. Proc. Nat. Acad. Sci. USA 115: 355-360.

VAN WIJHE, J.W. (1883). Ueber die Mesodermsegmente und die Entwicklung des Selachierkopfes. Verh. Acad. Setensch. 22: 1-50.

WADDINGTON, C.H. (1932). Experiments on the development of chick and duck embryos, cultivated in vitro. Philos Trans $R$ Soc Lond B 221.

WADDINGTON, C.H. (1933). Induction by the primitive streak and its derivatives. J. Exp. Biol. 10: 38-46.

WILSON, S.I., GRAZIANO, E., HARLAND, R., JESSELL, T.M. and EDLUND, T. (2000). An early requirement for FGF signalling in the acquisition of neural cell fate in the chick embryo. Curr Biol 10: 421-429.

WODA, J.M., PASTAGIA, J., MERCOLA, M. and ARTINGER, K.B. (2003). DIx proteins position the neural plate border and determine adjacent cell fates. Development 130: $331-342$

WRIGHT, T.J. and MANSOUR, S.L. (2003). Fgf3 and Fgf10 are required for mouse otic placode induction. Development 130: 3379-3390.

XU, H., DUDE, C.M. and BAKER, C.V.H. (2008). Fine-grained fate maps for the ophthalmic and maxillomandibular trigeminal placodes in the chick embryo. Dev Biol. 317: 174-186.

XU, P.X. (2013). The EYA-SO/SIX complex in development and disease. Pediatr Nephrol 28: 843-54.

YANG, L., ZHANG, H., HU, G., WANG, H., ABATE-SHEN, C. and SHEN, M.M. (1998). An early phase of embryonic DIx5 expression defines the rostral boundary of the neural plate. J Neurosci 18: 8322-8330.

ZHU, C.C., DYER, M.A., UCHIKAWA, M., KONDOH, H., LAGUTIN, O.V. and OLIVER, G. (2002). Six3-mediated auto repression and eye development requires its interaction with members of the Groucho-related family of co-repressors. Development 129: 2835-2849. 


\section{Further Related Reading, published previously in the Int. J. Dev. Biol.}

\section{Mechanisms of cranial placode assembly}

Marie Anne Breau and Sylvie Schneider-Maunoury

Int. J. Dev. Biol. (2014) 58: 9-19

https://doi.org/10.1387/ijdb.130351mb

Clonal analyses in the anterior pre-placodal region: implications for the early lineage bias of placodal progenitors

Sujata Bhattacharyya and Marianne E. Bronner

Int. J. Dev. Biol. (2013) 57: 753-757

https://doi.org/10.1387/ijdb.130155mb

Patterning and cell fate in ear development

Berta Alsina, Fernando Giraldez and Cristina Pujades

Int. J. Dev. Biol. (2009) 53: 1503-1513

https://doi.org/10.1387/ijdb.072422ba

The first steps towards hearing: mechanisms of otic placode induction

Takahiro Ohyama, Andrew K. Groves and Kareen Martin

Int. J. Dev. Biol. (2007) 51: 463-472

https://doi.org/10.1387/ijdb.072320to

The preplacodal region: an ectodermal domain with multipotential progenitors that contribute to sense organs and cranial sensory ganglia

Andrea Streit

Int. J. Dev. Biol. (2007) 51: 447-461

https://doi.org/10.1387/ijdb.072327as

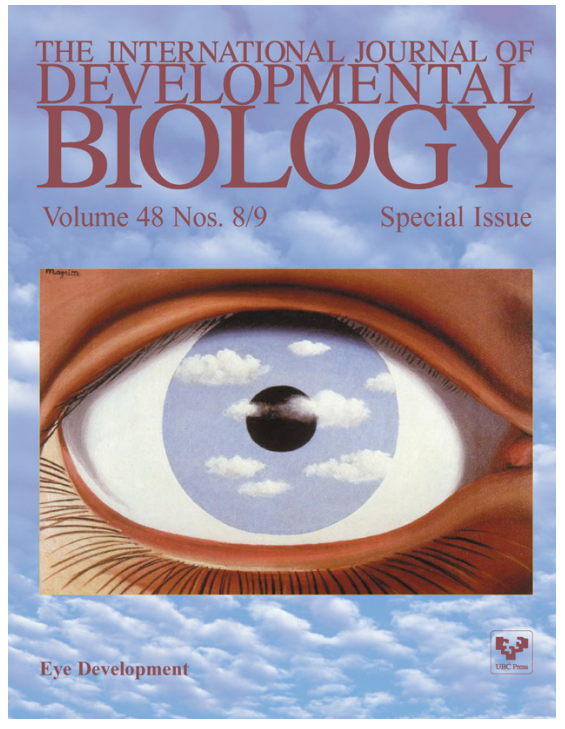

5 yr ISI Impact Factor $(2016)=2.421$
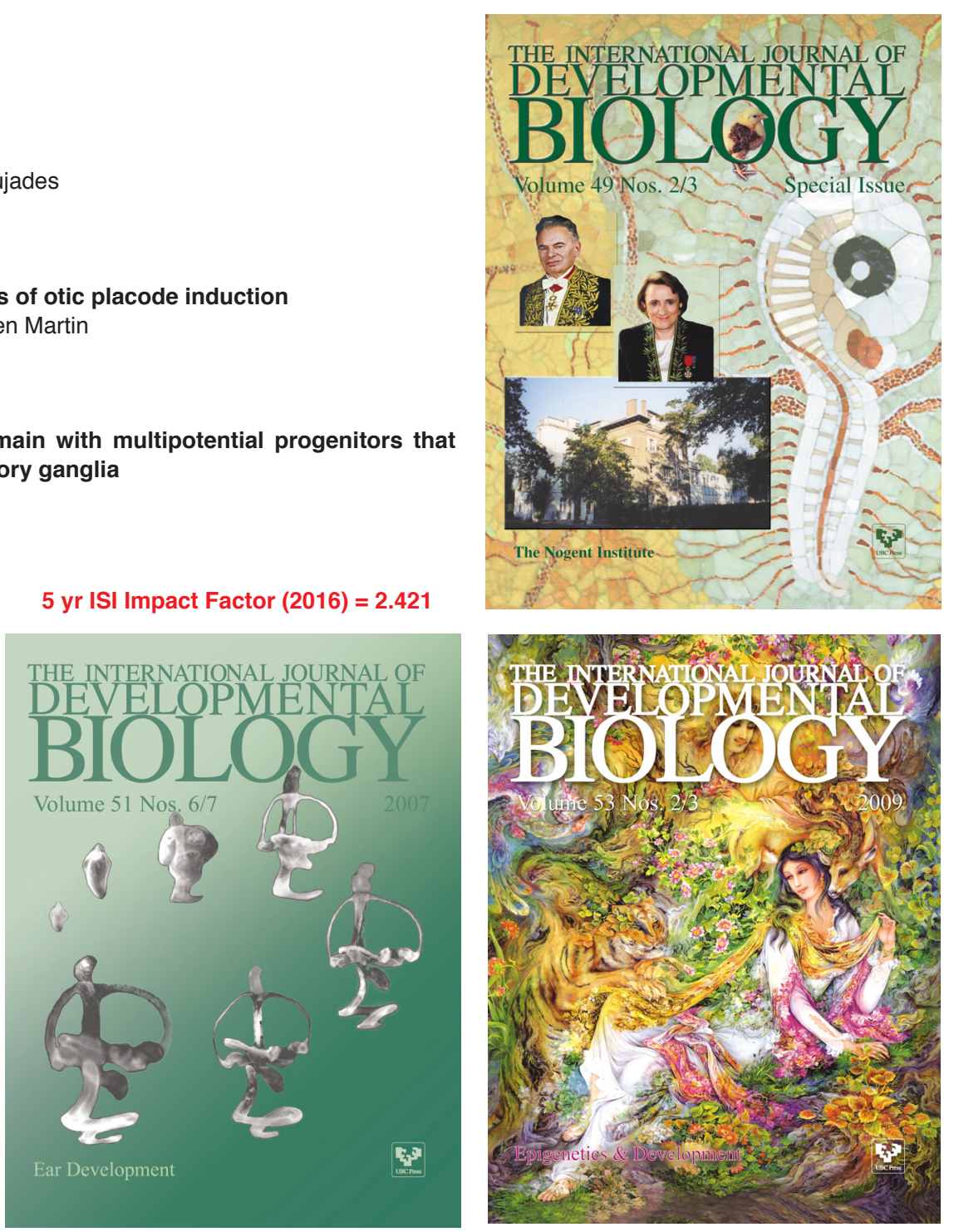